\section{Unusual duodenal perforation following endoscopic retrograde cholangiopancreatography}

\author{
Martin Kobborg, Per Helligso, \\ Peter Altmann, Mark Berner Hansen \\ Department of Surgery Hospital
}

of Southern Jutland, Aabenraa, Denmark

\section{Abstract}

Perforation is a known but rare complication to Endoscopic retrograde cholangiopancreatography (ERCP) with endoscopic sphincterotomy (ES). Most of the perforations are located in the periampullary area due to ES. This report presents an unusual perforation in the third part of the duodenum following ES. The patient an eigthy-sixt-year-old man underwent ERCP with ES. The patient had Magnetic Resonance Cholangio-pancreatography (MRCP) and Computerized Tomography (CT) verified cholelithiasis and intra- and extrahepatic cholestasis. The perforation was not found under the ERCP procedure but was clinically revealed when the patient developed pneumoscrotum after the procedure. A CT-scan with oral contrast later confirmed the duodenal perforation.

\section{Introduction}

Endoscopic retrograde cholangiopancreatography (ERCP) with endoscopic sphincterotomy (ES) is an advanced procedure with an overall 1-month morbidity of about $10 \%$ and a 1-month mortality of about $1 \%{ }^{1,2}$ Perforation is a serious complication to ERCP and usually related to ES and instrumentation of the biliary and pancreatic ductal systems. ${ }^{3}$ We present an unusual case with pneumomediastinum, pneumothorax and pneumoscrotum following ERCP and ES due to a duodenal perforation in the third part of the duodenum.

\section{Case Report}

An eighty six year old man with a history of diabetes mellitus, arterial hypertension and previous cerebral stroke presented with symptoms of cholestasis and slightly increased levels of basic phosphatase. Imaging with magnetic resonance cholangiopancreatography (MRCP) and computerized tomography (CT) demonstrated cholelithiasis and intra- and extra hepatic cholestasis. Following an appar- ently uncomplicated ERCP and ES without any technical problems, a 6-7 mm stone was extracted from the common bile duct, using a balloon catheter. One hour after returning to the ward, the patient complained of epigastric and genital pain. Examination revealed a tender epigastria region and crepitation (subcutaneous emphysema) from the neck down to the scrotum, which was enlarged and tender.

A chest and abdominal CT-scan with intravenous contrast revealed retroperitoneal emphysema, emphysema in the scrotum and subcutaneously in the groins (Figure 1). Furthermore the CT-scan revealed a $2 \mathrm{~cm}$ wide pneumothorax at the right side and pneumomediastinum (Figure 2).

Because of suspicion of duodenal perforation following the ES, the patient was treated with a nil-by-mouth regimen, intravenous fluids, antibiotics and analgesics. The patient's condition worsened on post-ERCP day 2 . In particular, his respiratory condition deteriorated and serum C-reactive protein levels increased significantly.

As no clinical improvement was observed, another CT-scan was performed on post-ERCP day 5 with both oral and intravenous contrast. Surprisingly, it revealed oral contrast leakage into the peritoneal cavity from the third part of the duodenum (Figure 3).

In view of the patient's poor clinical condition, it was not possible to operate the patient and after consultation with the family, invasive treatments were stopped on post-ERCP day 6 . The patient died on post-ERCP day 7 .

\section{Discussion}

The incidence of perforation following ES is about $2 \% 1-3$ and may be a life-threatening complication to ES.1,2 About half of the perforations are in the periampullary area primarily following ES and about one-third of the perforations are in the bile or pancreatic duct systems following guide-wire procedures. The remaining perforations are in other areas of the duodenum. ${ }^{3-5}$ In the present case, a CT-scan revealed no leakage of contrast from the first and second part of the duodenums, and particularly not in the periampullary area. Instead CT revealed contrast leakage to the peritoneal cavity from the third part of the duodenum.

The mechanism of perforation in the third and fourth part of the duodenum is uncertain. The cause for the duodenal perforation was probably related to a mechanical pressure from the endoscope on the duodenal wall or a stretch on the duodenal wall from the endoscope during the maneuver for getting into canulation position. The duodenal wall may have been unusual fragile due to the patient's cardiovascular comorbidities and advanced age..$^{6,7}$
Correspondence: Martin Kobborg, Jyllandsgade 47, 2. th. 7000 Fredericia, Denmark.

E-mail: martin@mkobborg.dk

Key words: gastrointestinal endoscopy.

Received for publication: 16 November 2010 .

Revision received: 7 January 2011.

Accepted for publication: 10 January 2011.

This work is licensed under a Creative Commons Attribution 3.0 License (by-nc 3.0).

@C Copyright M. Kobborg et al., 2011

Licensee PAGEPress, Italy

Gastroenterology Insights 2011; 3:e1

doi:10.4081/gi.2011.e1

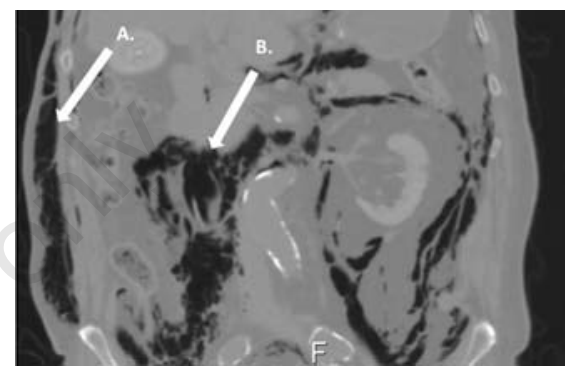

Figure 1. Abdominal CT-scan on postERCP day 1. (A) Subcutaneous emphysema. (B) Free retroperitoneal air.

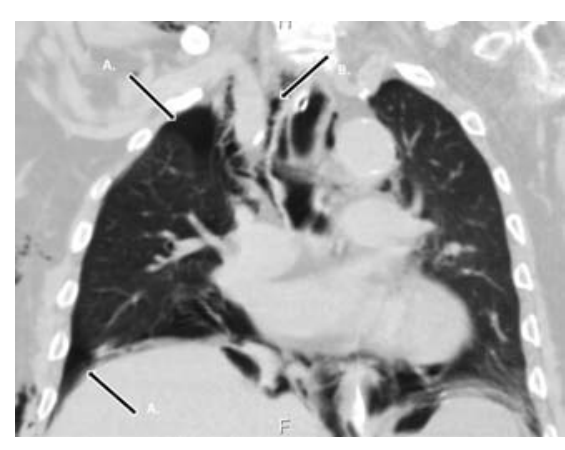

Figure 2. Chest CT-scan post-ERCP day 1. (A) Pneumothorax on the right side. (B) Pneumomediastinum.

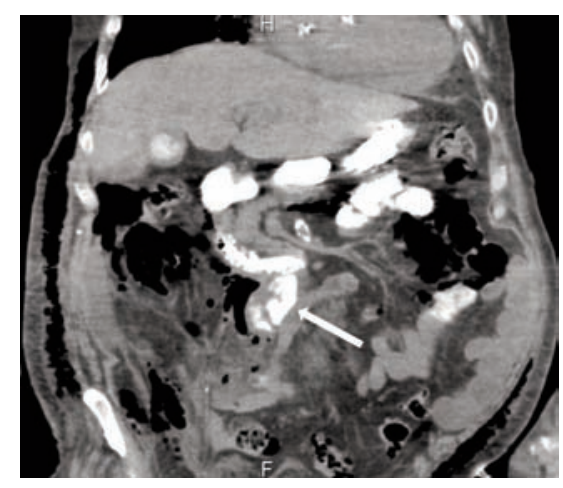

Figure 3. Abdominal CT-scan post-ERCP day 5. Leakage of contrast into the peritoneal cavity from the third part of the duodenum. 
Pneumoscrotum was recognized both clinically and by CT-scan. The pathways that enable air to accumulate in the scrotum are numerous and diverse. ${ }^{8}$ In the present case, we believe that the major mechanism for the pneumoscrotum was the retroperitoneal air coming from the perforation in the duodenal wall. Free air from the retroperitoneal space can reach into the scrotum along the spermatic fascia. ${ }^{8}$ Retroperitoneal air can spread through deep fascial planes to subcutaneous tissue and develop subcutaneous emphysema.

The location of perforation in the present case was not revealed before oral contrast was applied to the CT scan at post-ERCP day 5 . However, even in absence of an identified duodenal perforation, it is possible to develop emphysema after an ERCP. This can be explained by a mucosal disruption following increased intraluminal pressure after air inflation or a small iatrogenic perforation not detected by the conventional imaging techniques. $^{9}$

An ERCP related perforation could be managed in different ways depending of the location of the perforation and the patient's clinical condition. Periampullary and guide wire perforations may be managed no surgically with close surveillance. At no surgical management the patient is treated with intravenous antibiotics, fluids and a nil-by-mouth regimen (as was done in the present case). Perforations in the other parts of duodenum usually require immediate surgery. 4,5 When a patient, with a large duodenal perforation, is inopera- ble due to for example an advanced age and comorbidities, it is possible to try to repair the perforation endoscopic with endoclips. ${ }^{10}$ Finally, using gentle low-risk techniques (e.g. guide wire) together with deep sedation or even universal anesthesia for patients with identified risk factors for ERCP related perforation (e.g. sphincter of Oddi dysfunction, sphincterotomy, stricture dilation, and long duration of the procedure ${ }^{4}$ ) are maneuvers likely to reduce the risk of duodenal perforation. In conclusion we report a case of a duodenal perforation at a rare location, the third portion. Clinically the suspicion of a perforation was revealed by pneumoscrotum. Aggressive diagnostics with both oral and intravenous contrast at abdominal and chest CT scans are advocated on suspicion of perforation or other serious complication following ERCP.

\section{References}

1. Freeman ML, Nelson DB, Sherman S, et al. Complications of endoscopic biliary sphincterotomy. N Engl J Med 1996;335: 909-18.

2. Barthet M, Lesavre N, Desjeux A, et al. Complications of endoscopic sphincterotomy: results from a single tertiary referral center. Endoscopy 2002; 34:991-7.

3. Howard TJ, Lehman GA, Sherman S, et al. Classification and management of perforations complicating endoscopic sphinc- terotomy. Surgery 1999;126:658-63.

4. Enns R, Eloubeidi MA, Mergener K, et al. ERCP-related perforations: risk factors and management. Endoscopy 2002;34:2938.

5. Stapfer M, Selby RR, Stain SC, et al. Management of duodenal perforation after endoscopic retrograde cholangiopancreatography and sphincterotomy. Ann Surg 2000;232:191-8.

6. Warren JL, Klabunde CN, Mariotto AB, et al. Adverse events after outpatient colonoscopy in the medicare population. Ann Intern Med 2009;150:849-57.

7. Fernandez AZ, DeMaria EJ, Tichansky DS, et al. Experience with over 3,000 open and laparoscopic bariatric procedures: multivariate analysis of factors related to leak and resultant mortality. Surg Endosc 2004;18: 193-7.

8. Firman R, Heiselman D, Lloyd T, Mardesich P. Pneumoscrotum. Ann Emerg Med 1993;22:1353-6.

9. Mosler P, Fogel EL. Massive subcutaneous emphysema after attempted endoscopic retrograde cholangiopancreatography in a patient with a history of bariatric gastric bypass surgery. Endoscopy 2007;39:E155.

10. Nakagawa Y, Nagai T, Soma W, et al. Endoscopic closure of a large ERCP-related lateral duodenal perforation by using endoloops and endoclips. Gastrointest Endosc 2010;72:216-7. 